\title{
TOWARDS NEUROSUBTYPES IN AUTISM
}

Seok-Jun Hong ${ }^{1}$, Joshua T. Vogelstein ${ }^{2}$, Alessandro Gozzi ${ }^{3}$, Boris C. Bernhardt ${ }^{4}$, B.T. Thomas Yeo ${ }^{5,6,7,8}$, Michael P. Milham ${ }^{1,9}$, Adriana Di Martino ${ }^{10}$

${ }^{1}$ Center for the Developing Brain, Child Mind Institute, NY, USA; ${ }^{2}$ Department of Biomedical Engineering Institute for Computational Medicine, Kavli Neuroscience Discovery Institute, Johns Hopkins University, MD, USA; ${ }^{3}$ Functional Neuroimaging Laboratory, Center for Neuroscience and Cognitive Systems, Istituto Italiano di Tecnologia, Rovereto, Italy; ${ }^{4} \mathrm{McConnell} \mathrm{Brain} \mathrm{Imaging}$ Centre, Montreal Neurological Institute and Hospital, McGill University, QC, Canada; ${ }^{5}$ Department of Electrical and Computer Engineering, Center for Sleep and Cognition, Clinical Imaging Research Centre, N.1 Institute for Health, National University of Singapore; ${ }^{6}$ Centre for Cognitive Neuroscience, Duke-NUS Medical School, Singapore; ${ }^{7}$ NUS Graduate School for Integrative Sciences and Engineering, Singapore; ${ }^{8}$ Martinos Center for Biomedical Imaging, Massachusetts General Hospital, MA, USA; ${ }^{9}$ Center for Biomedical Imaging and Neuromodulation, Nathan Kline Institute, NY, USA; ${ }^{10}$ Autism Center, Child Mind Institute, NY, USA

\section{CORRESPONDING AUTHOR}

Adriana Di Martino, MD

Autism Center, Child Mind Institute

101 East 56th Street, New York, NY 10022

E-mail: Adriana.DiMartino@,childmind.org

Running title: Towards neurosubtypes in autism

KEYWORDS: Data-driven clustering, Bayesian modeling, Replicability, Neuroimaging, Autism, subtyping 


\begin{abstract}
There is a general consensus that substantial heterogeneity underlies the neurobiology in autism spectrum disorder (ASD). As such, it has become increasingly clear that a dissection of variation at the molecular-, cellular-, and system-level domains is a prerequisite for identifying biomarkers and developing more targeted therapeutic strategies in ASD. Advances in neuroimaging approaches to characterizing atypical brain patterns have recently motivated their application as viable tools to delineate more homogenous ASD subgroups at the level of brain structure and function - i.e., neurosubtyping. This review assesses and critically discusses the current datadriven neurosubtyping in ASD. It breaks this pursuit into key methodological steps: the selection of diagnostic samples, neuroimaging features, algorithm and validation approaches. For each step, we appraise the current literature in terms of progress, as well as remaining challenges and potential solutions. Convergence across findings is discussed and biological implications are highlighted. Although preliminary and with limited methodological overlap, results from this literature illustrate the feasibility of neurosubtyping. Across studies, there is general agreement that distinct neurosubtypes exist, but the exact number and their definitions vary depending on the specific features and approach utilized in a given study. Results also suggest the utility of subtypes in predicting symptom severity and diagnostic labels above and beyond group-average comparison designs. This review concludes with a discussion of future avenues towards a comprehensive understanding of the mechanisms underlying ASD heterogeneity.
\end{abstract}




\section{INTRODUCTION}

Clinical and etiological heterogeneity remain major obstacles for advancing biomarker identification in psychiatry. Recognizing the limitations of current nosology $(1,2)$, the past decade has witnessed pressing calls to partition psychiatric heterogeneity into more homogenous groups - i.e. subtyping (3-8). Here, we spotlight Autism Spectrum Disorder (ASD), which with its early childhood onset (9), remarkable clinical and biological variability $(10,11)$, and consistently increasing prevalence (12), epitomizes psychiatry's needs and challenges in subtyping.

Unlike other psychiatric disorders characterized by a spectrum of symptom severity and shared variance (e.g., schizophrenia, mood, and anxiety; 13, 14), individual variation in ASD goes beyond core diagnostic symptoms (i.e., impairment in social communicative skills, restricted/repetitive behaviors/interests) and associated psychopathology $(15,16)$. In particular, ASD is often complicated by accompanying heterogeneity in the type of onset (9), language skills $(17,18)$, intellectual abilities (19), and medical conditions (20). While high variability in behavioral presentation of ASD has been reported since its early description in 1940's $(21,22)$, increases in prevalence (from $0.05 \%$ in 1966 to $2 \%$ in $2019 ; 23,24$ ) over the past 40 years have likely led to further unveiling its heterogeneity. This is due to some of the factors contributing to increased prevalence - most notably, greater recognition in individuals with typical intelligence (25) and diagnostic substitution (26). Evidence of more heterogenous ASD being detected come from a recent meta-analysis showing that effect size for diagnostic group mean differences in ASD have decreased over time; this is in contrast with stable effect size observed in schizophrenia, a heterogeneous condition without prevalence changes (27). The uniqueness of ASD is further accentuated by its onset in the first years of life combined with a long-term 
course. This is substantiated by dramatic variation in ASD developmental trajectories $(17,28$ 32), resulting functional outcomes (33) and response to treatment (34) - all of which underscore the need for a strong developmental perspective in subtyping approaches. The complexity of the picture for ASD is highlighted by advances in genomics and neurobiology studies, which have collectively pointed towards multiple etiological pathways $(11,35)$. In sum, the resulting range of clinical and biological ASD presentations represents both a formidable challenge and motivation for subtyping.

Subtyping approaches can be characterized in terms of both the unit(s) of analysis upon which variation among individuals is indexed, and the nature of the algorithm(s) being used to sort individuals into groups (FIGURE S1). Target units of analyses can be largely categorized under behavior and biology $(36,37)$. The behavior-based levels are thought to indirectly index variation of underlying biology $(38,39)$ and vice versa. Regardless of the unit(s) of analyses, quantitative subtyping algorithm can be broadly categorized as supervised (i.e., label-driven), unsupervised (i.e., data-driven), or their hybrids $(38,40)$. These approaches leverage univariate or multivariate statistics, each having advantages and disadvantages as detailed elsewhere (4143).

In ASD, until recently, behavior has been the predominant unit of analysis, whether using theoretically-motivated $(44,45)$ or data-driven approaches $(4)$. While the results of these efforts have captured relevant clinical aspects of autism, their findings have been neither exhaustive, nor reliably distinguishable (46). As such, the DSM-5 (47) and the newest version of the ICD (48) have retreated to a single diagnostic category of ASD. This underscores the need for more 
detailed behavioral phenotyping (10), and a substantial gap in identifying subtypes anchored to biological features relevant to etiology and/or pathophysiology.

In other fields of medicine, the detection of biologically-based subtypes has led to earlier and more accurate recognition, more precise treatment selection, and outcome monitoring (e.g., congestive heart failure; 49). While the differing pathophysiology and etiologies of ASD remain to be fully elucidated, owing to the pivotal contribution of genetic factors to ASD risk (heritability: $0.69-0.83 ; 50$ ), genomic analyses have led endeavors aimed to identify biologicallydriven subtypes (detailed in 11, 51). A number of emerging models examined the contribution of genetic etiology on ASD, including candidate genes (35), common and rare variants $(51,52)$. Whole-exome sequencing studies have identified approximately 90 genes, with rare and mostly de novo variants conferring a relatively higher risk of $\operatorname{ASD}(53,54)$. As a result, genetics-first approaches, whereby specific genotypes represent the target unit for subtyping, have arisen (55, 56). Although promising, the high genotype-to-phenotype variability, the different penetrance between common and rare variants, the low prevalence of any single variant/mutation (1-2\% of ASD cases; 57; though cumulatively, all identified ASD-related gene mutations contribute to about $20 \%-40 \%$ of clinical non-syndromic ASD) all represent barriers to efforts focused on genetic approaches alone to discover clinically relevant subtypes.

Recognizing these challenges, researchers have begun to explore the utility of complementary biological target units of analysis, bringing a range of biophysical indices of brain function into focus (58). Among them, neuroimaging is emerging as a robust tool to capture ASD pathophysiology (59), and is theoretically well positioned to establish subtypes that can be linked to behavioral and/or biological variation. Accordingly, this review selectively focuses on the 
nascent data-driven ASD literature aimed to identify homogeneous subgroups based on neuroimaging features - hereafter referred to as neurosubtyping.

\section{DATA-DRIVEN ASD NEUROSUBTYPING}

The present ASD neurosubtyping literature is in its infancy with a total of 12 studies in humans, 92\% published since 2018 (60-71). Studies vary in methodology (FIGURE 1, TABLE 1). As such, we stratify this review based on key methodological components (FIGURE 2), with each section highlighting existing limitations and future avenues. A summary of converging findings follows. Briefly, across studies, findings revealed the presence of at least 2-4 ASD neurosubtypes. Each represented different proportions of subjects, suggesting that traditional case-control group means can miss information about the less represented subtype(s) in a given sample. This has likely contributed to the apparent inconsistencies in traditional group comparisons (72). Suggesting their clinical validity, most studies reported distinct association of neurosubtypes with clinical behavioral features. Finally, as discussed below, although the features examined varied across studies, their spatially distributed nature suggests the relevance of a system neuroscience approach.

\section{Diagnostic samples}

Current literature. Seven of the 12 studies (59\%) neurosubtyped individuals with a confirmed ASD diagnosis separately from neurotypicals (NT), and three examined ASD and NT data together. Only two examined transdiagnostic samples. The advantage of solely focusing on ASD is that it allows the parsimonious detection of ASD neurosubtypes that may serve as clinical biomarkers. However, as variability also exists within NT, at the very least some standardization 
of ASD data is recommended to determine the extent to which findings are ASD-specific. Three studies normalized the metrics against NT data before neurosubtyping (e.g., structural features; $62,65$, or z-scores of intrinsic functional connectivity [iFC]; 71$)$. Others $(60,67,68)$ have opted to identify neurosubtypes across both ASD and NT datasets, with the assumption that ASDrelated pathophysiology may occur in addition to, and interacting with, differing neurosubtypes observed in the population. Building on these considerations, and consistent with transdiagnostic perspectives in psychiatry (73), two neurosubtyping studies have combined ASD with other psychiatric conditions - schizophrenia spectrum disorders, bipolar disorder, and NT in (67) and ADHD and NT in (68).

Remaining challenges, possible solutions. Findings from these early transdiagnostic studies (67, 68) suggest that common sources of neurophenotypic variation in ASD extend across diagnostic boundaries (TABLE 1). For example, Stefanik, et al. (67) identified four neurosubtypes, each including multiple diagnoses at different prevalence and characterized by distinct patterns of anatomical features. Transdiagnostic commonality can result from different scenarios including additive mechanisms (i.e., pathologic processes occurring in addition to those specific to a given condition) or pleiotropy (i.e., shared underlying mechanisms displaying as distinct clinical phenotypes). These scenarios can be disentangled via widely and deeply characterized large samples to examine continuous psychological and biological dimensions. Such endeavors require significant resources that are, however, taxing for single sites (74). Currently, sample sizes in ASD neurosubtyping studies ranged from $n=44$ to $n=900+$ datasets. The largest samples result from retrospective data aggregation or from prospective multicenter collections - the Autism Brain Imaging Data Exchange (ABIDE-I \& -II; 75, 76), and EU-AIMS Longitudinal European 
Project (77), respectively. TABLE 2 summarizes neuroimaging datasets $(56,78-80)$ usable for discovery and/or replication (see 81 ).

\section{Features}

Current literature. All studies focused on a single neuroimaging modality, primarily structural or functional MRI, except two EEG studies $(61,69)$. Within imaging modality, the type and number of features varied (e.g., iFC, EEG coherence, cortical thickness, mean diffusivity; TABLE 1). High variability of features reflects the challenge of establishing an optimal set of variables, and the lack of consensus on what features are most relevant for ASD neurobiology. Features were predominantly selected based on data availability and/or prior knowledge. In one example, indices of cortical organization were selected based on previous postmortem histological and in vivo neuroimaging findings (FIGURE 4A; 82, 83, 84). Only one study used a quantitative method for feature selection (61). Specifically, Duffy, et al. clustered their sample among 40 EEG coherence factors selected based on their accuracy in discriminating ASD from NT (85). This feature selection approach can be categorized as a 'filter-method' $(86,87)$, a group of methods selecting features based on their relevance, here to ASD. Although computationally efficient and scalable, most filter-methods assess each feature separately, thereby ignoring inter-feature dependencies. Though their independence from the subtyping algorithm can be a strength, it may also lead to selecting features that are suboptimal for subtyping quality (86). To address this limitation, other quantitative approaches select features based on their usefulness to the specific question of interest; they are referred to as 'wrapper' (e.g., sequential search) or 'embedded' (e.g., random forest) $(86,87$ for reviews). These methods are yet to be applied to ASD neurosubtyping, though promising proof of concepts are below $(38,40)$. 
One critical consideration for feature selection is data reduction. Although deeply characterized samples, with a high number of features to explore across multiple modalities are theoretically desired, data with more feature dimensions than subjects create a statistically ill-posed problem, i.e., an infinite number of solutions can fit data equally well. Many subtyping algorithms rely on distance metrics quantifying how far the data points are from each other. As the dimensionality gets larger, the inter-point distance becomes less discernible (i.e., more uniform). Therefore, high dimensionality can become toxic (88). To date, only two ASD neurosubtyping studies quantitatively addressed this challenge, one via principal component analysis (PCA; 61) in EEG data, another via non-negative matrix factorization (62).

A related question is how to optimally combine different data types. Current ASD studies focused on single neuroimaging modalities and none have combined neuroimaging with behavioral features, which instead have been used for validation. In one exception (67), similarity network fusion (89), a variant of multi-view multidimensional scaling (90), was applied to ASD and other diagnoses to combine demographic, brain imaging, and behavioral data (FIGURE S2B). After detecting inter-subject distances across all pairs of data domains, this approach jointly embedded those distances in a lower dimensional subspace. This process resulted in four transdiagnostic community structures showing distinct neurocognitive profiles. Although helpful, a caveat of similarity network fusion is its limited scalability to highly dimensional data (91). Additionally, since it assigns equal weights across features, this approach is sensitive to noise (92). 
Remaining challenges, possible solutions. To enable quantitative selection of those features most tied to the outcome of interest, two hybrid approaches are promising for ASD neurosubtyping. One is functional random forest (FRF; 38), the other is surrogate variable analysis (SVA; 40). FRF combines random forest (supervised) with community detection (unsupervised). Briefly, using random forest, FRF generates an ensemble of decision trees where each leaf node contains individuals that are highly similar with respect to a variable of interest. This information constructs a subject-wise proximity matrix, which is, in turn, fed into community detection. FRF has recently identified subtypes based on cognitive performance in children with ASD and NT (40). In contrast, SVA has not yet been applied to ASD, nor subtyping. Originally developed to remove unknown sources for batch effects in genomic data (40), SVA identifies and decomposes confounding sources using combining linear regression (supervised) and PCA (unsupervised). A common caveat of these methods is that one needs to select the appropriate relevant question for subtypes to be informative (3). In ASD, examples of relevant questions pertain to whether neuroconnectome subtypes reflect distinct genetic profiles, treatment responses, or different comorbidity risks. Future applications across multiple target unit of analysis are required to confirm FRF and SVA usefulness in ASD.

In relation to "multi-view learning" methods (93) that address the scalability limitation of similarity network fusion, notable examples include generalized canonical correlation analysis (GCCA) and Joint and Individual Variation Explained (JIVE) (94). GCCA is a generalization of PCA and linear regression to more "views" of the data. GCCA jointly learns a low-dimensional representation of each view (i.e., similarity matrix) that maximizes correlation between all pairs of views. An advantage is that it generates differential weights for each feature. JIVE (94) 
identifies variance components spanning multiple data types and their unique variation, thus it provides a comprehensive description of multi-source heterogeneity within and across data types. These two techniques have yet to be utilized in neurosubtyping but recent neuroimaging studies support their utility in predicting brain age or brain relationship with demographics and behavior $(95,96)$, as well as of extracting a low-dimensional representation of depression-related connectivity (97).

For any feature selection, two additional problems should be addressed. One is 'data leakage' (98): when feature selection and subtyping are dependent, thus artificially amplifying the quality of subtyping solution (“overfitting the model"). Any algorithm based on strict cross-validation, such as embedded methods, can bypass this risk by splitting the data into training and test cases. The second problem is related to employing features that exhibit inadequate reliabilities (e.g., across scans and/or scanners; 99). As in other neuroscientific disciplines, the neuroimaging field has, at times, forged ahead with features that were not properly assessed nor optimized for reliability. This is problematic because with the exception of core structural measures (e.g., volume, cortical thickness), most neuroimaging metrics have modest-to-moderate reliability (99). This increases the sample size needed to identify meaningful group-level findings and severely limits opportunities for individual-level analysis (see 100). Current ASD neurosubtyping literature examined some features with moderate to high test-retest reliability (e.g., cortical thickness: ICC $=0.6-0.8 ; 101,102,103)$. For other features, reliability remains unknown (e.g., gray/white matter intensity contrast). Efforts to optimize data acquisitions and analyses to improve reliability are underway and should be considered in ASD neurosubtyping. For example, in functional connectomics, increasing data acquisitions from $\sim 5$ to 30 minutes/subject 
has been shown to dramatically increase reliability, even if combining data across differing fMRI scan types (e.g., task, rest) $(104,105)$.

\section{Algorithms}

Current literature. Data-driven neurosubtyping in ASD has comprised three methods. Two of them include fully unsupervised approaches, such as clustering ( $\mathrm{n}=7$ studies) and latent factor analysis $(n=2)$, a third is normative modeling $(n=3)$.

i) Clustering partitions the data into a number of clusters such that the samples in each cluster are more similar to one another than to those in others. Reflecting its widespread popularity and relative computational ease, three ASD neurosubtyping studies $(60,62,63)$ have used k-means clustering - a centroid-based approach that iteratively assigns individual data points based on their 'closeness' to the centroid of each cluster. Others $(61,64,65)$ have used variants of hierarchical clustering that generate cluster trees using heuristic data splitting or merging (FIGURE S2A). Unlike k-means, hierarchical clustering does not require specifying cluster number beforehand. With hierarchical clustering, each branch of the tree tracks a sequence of progressive clustering processes, fully capturing the nested hierarchical data structures. On the one hand, this facilitates interpretation of neurosubtyping across multiple scales, as different subgroup resolutions can guide clinical decisions. On the other hand, k-means only needs to fit a few boundaries to data, while hierarchical clustering learns many more boundaries, potentially leading to suboptimal findings.

ii) Latent factor analysis. Two recent studies $(68,71)$ have used this approach by borrowing topic modeling techniques from natural language processing (FIGURE S2C). These models assume that 
each document (individual brain) is a collection of words (brain connectivity) associated with a subset of $K$ latent topics ( $K$ brain factors underlying ASD heterogeneity). One advantage of topic modeling approaches is that they automatically summarize high dimensional individual data into a combination of parsimonious latent structures. In this way, they allow each individual to express multiple latent brain factors to differing degrees, which potentially reflects heterogeneous underlying pathologies. Thus, the advantage of this approach is that it quantitatively describes both categorical and dimensional aspects of ASD heterogeneity. Other techniques capturing this hybrid information, such as soft clustering (106), have not been applied to ASD neurosubtyping. These, along with model-based clustering algorithms, such as latent Dirichlet allocation, may provide more accurate quantitative biomarkers of ASD.

iii) Normative modeling. This alternative approach has been applied to various conditions, including ASD (107). By estimating the quantiles of variation for a brain metric in a given population, normative modeling statistically infers each individual deviation from the normative pattern (FIGURE S2D). The identification of the extreme cases in the distribution is used to find a subgroup of individuals that are more clearly separable from all others, and possibly more homogenous. To date, three ASD neuroimaging studies $(66,69,70)$ have adopted this approach. Focusing on either cortical thickness $(66,70)$ or alpha-wave EEG profiles deviation from normative curves derived from cross-sectional age data (69), their results showed that variability between ASD and NT is largely overlapping and only a subset of individuals shows a high degree of brain atypicalities. One disadvantage of this method is that it does not assume that there are multiple subgroups. Conversely, it highlights a deviation score for each individual rather than a group mean, a concept in line with highly desired precision medicine (4). Another 
caveat of this approach is that estimating high-dimensional distributions requires an exponentially increasing number of data points as the number of dimensions increases. Since this cannot be practically done in the native dimensionality of neuroimaging data, a smaller number of features must be selected relative to other algorithms that do not need to estimate the full distribution, but only partitions of the space. Therefore, choosing the right features is more important for normative modeling.

\section{Validation}

Current literature. Regardless of the specific feature or subtyping algorithm employed, within a given study, a range of assumptions are made and parameters estimated. As such, there is no single 'one-size-fits-all' subtype solution. Different approaches have been developed to directly estimate optimal solutions within the same dataset (108 for review). Some have been used in current ASD neurosubtyping (e.g., Silhouette; 62, Davies-Bouldin index; 65). Others indirectly validate the subtype solutions by assessing their stability, either across independent subtyping algorithms or via bootstrapping. So far, only two ASD neurosubtyping studies have assessed the convergence of findings from different algorithms $(61,71)$ and four have used bootstrapping $(60$, $65,66,71)$, all reported within-study stability.

Different solutions can be equally meaningful, with each capturing a distinct aspect of the data (109). Thus, a common within-sample strategy for validation is to demonstrate that identified neurosubtypes explain variation in measures other than the features employed for subtyping. These can encompass biological and/or clinical variables. In the present ASD literature, such validation method has been primarily based on clinical and demographic metrics. Although 
preliminary, initial results suggest that the identification of neurosubtypes may be promising to better explain brain-behavior relationships in regard to symptom severity (65) or diagnostic labels (62). Four studies used independent neuroimaging modalities $(62,65,67,69)$. By validating neurosubtypes identified via regional structural features with specific brain connectivity metrics, these studies point towards neurosubtype-specific associations to both regional and large-scale brain organization.

Remaining challenges, possible solutions. An existing gap towards clinically relevant validation of ASD neurosubtypes is to assess their relation to clinical outcomes. The utility of this approach has been shown in Alzheimer's and Depression, whereby neurosubtype-specific outcomes have been revealed based on naturalistic prospective and treatment data, respectively $(97,110)$. Longitudinal datasets also allow to assess the stability of a subtype solution over time; developmentally stable subtypes are likely to represent heterogeneity of disease traits. In contrast, unstable subtypes may reflect variation in developmental stages and/or disease progression. Unfortunately, in ASD, no longitudinal data have been used for either data-driven neurosubtyping nor validation. This likely reflects their limited availability which should be a mandatory future focus (111). Meanwhile at the bare minimum, preliminary investigation can be carried on cross-sectional datasets.

Additionally, mostly due to compliance requirements for neuroimaging data collection, the field has largely failed to include less cognitively capable individuals, thus limiting the generalizability of findings. Future studies must invest in protocols that allow data collection across all abilities, including natural sleep scans $(112,113)$, passive viewing $(114,115)$, scan 
behavioral preparation (116), as well as technical advancements addressing head motion prospectively $(117,118)$. Another challenge germane to ASD is the disproportional representation of males (119). While sex-related differences may contribute to ASD biological heterogeneity $(120,121)$, the higher prevalence of males with ASD and the tendency of single site studies to exclude, or minimally represent females may limit generalizability of neurosubtypes. Fortunately, prospective studies explicitly over-recruiting females are ongoing (122) and large-scale data repositories are amassing larger female data (76).

Like any clinically useful biomarkers, high precision (low false positive rate), recall (low false negative rate), and most importantly, replicability (the degree to which identical findings are obtained in a distinct sample with similar methods) are key requirements (99). Unfortunately, many fields including neuroscience and psychology are currently experiencing a replicability crisis $(123,124)$. Two factors contribute: sample size and measurement reliability (100). Statistical strategies to increase replicability exist, even if the reliability of features is not excellent. A representative one is 'bagging' (i.e., bootstrap aggregating), a technique that aggregates randomly selected subsamples to reduce the variability of the measurement through averaging (125). A recent study applying bagging to brain parcellation demonstrated substantially improved reproducibility and test-retest reliability (126). A similar idea can be applicable to neurosubtyping by running the clustering algorithm on thousands of bootstrap samples. Averaging across bootstrap-derived clustering yields a consensus matrix $(127,128)$ representing how consistently a pair of individuals was subgrouped together. Thus, bagging can improve both consistency and reliability of neurosubtypes within a given sample. This comes with high cost in computation and, possibly, interpretability. One more general caveat is that 
bagging cannot overcome limitations of the sample population, for example, if it is a biased sample, naive bagging will not reduce the bias. More sophisticated stratified resampling techniques can mitigate these biases.

Replicability is also affected by high variance coming with large multisite datasets. This socalled batch effect can be attenuated by harmonization processes, namely PCA-based data reconstruction method (129) or ComBat (i.e., Combining Batches) (130). ComBat, originally developed in the genomic field, is based on a linear model involving the site as a main (additive and multiplicative) statistical term. The model reduces the site effects based on statistical correction and reconstructs a minimized-site-effect dataset (see 131 for discussion on residual site effects). Compared to conventional regression-based correction, ComBat is more robust to outliers in small samples, as it uses an empirical Bayes approach to estimate site/time collection effects. Significance-weighted PCA is another mitigation approach that involves performing PCA over the whole images, and then computing the statistical significance of each component in relation to a site. An initial application successfully obtained site-variable weighted subnetworks, in an ASD non-subtyping study (129). To facilitate replication for core findings in ASD, as well as to promote discovery, we draw attention to and detail existing neuroimaging ASD data repositories in TABLE 2.

\section{Converging findings, future avenues}

Although the ASD neurosubtyping literature to date is preliminary, some convergence in findings is beginning to emerge. First, most of the ASD neurosubtypes so far identified a combination of ASD-related increases and decreases in any neuroimaging feature examined. 
Second, regardless to the features examined, no ASD neurosubtype has been characterized by a spatially isolated (focal) pattern; instead atypicalities are spatially distributed. In this regard, a set of regions within the default and fronto-parietal networks are largely consistent across neurosubtyping studies (FIGURE S3), an observation that is consistent with resting-state fMRI findings by Tang, et al. (71). Given that higher-order social and cognitive processes are affected in ASD $(132,133)$, we suggest that the common involvement of these network(s) may underlie shared impairment in core ASD symptoms. The subtype-specific pattern of atypicality within these networks (i.e., increases and/or decreases in a given feature) may differentially affect symptom severity and specific presentation. On the other hand, the degree to which atypicalities involve other networks more sporadically observed across neurosubtypes (e.g., visual, dorsal attention networks) may be associated with inter-individual differences in comorbid symptoms. Testing this hypothesis requires combining neuroimaging with phenotypic characterization of both ASD core and comorbid symptoms - a procedure not common in ASD neuroimaging, with few exemplary exceptions $(76,134-137)$.

The distributed nature of neural atypicalities in ASD neurosubtypes point towards mechanisms affecting large-scale brain organization. Thus, measures of brain connectivity (e.g., iFC, structural covariance, EEG coherence) may more directly guide towards the biology underlying ASD heterogeneity. A range of models of atypical connectivity in ASD exist, including decreased long- $v s$. increased short-range (138), imbalanced intra- vs. inter-modular (139), atypical shifts toward cortical-subcortical (140), and idiosyncratic connectivity (141). More recently, atypical cortical connectome hierarchy has been proposed to recapitulate most of the 
patterns above (142). Testing these models in the context of neurosubtyping may provide greater insight into their biological relevance in ASD heterogeneity.

A remaining challenge is to bridge macroscale brain phenomenology to microscale underlying mechanisms (i.e., cellular, molecular, genetic). Although the cognitive and socio-communicative domains affected by ASD are human-specific and cannot be comprehensively recapitulated by any animal model, research using model organisms amenable to genetic manipulation offers one means to bridge these two different scales. At present, a macaque model of one genetic variant observed in humans with ASD has been reported (143), and a larger number of models are available in the laboratory mouse (144-146). The application of translationally relevant neuroimaging across these models may reveal neurosubtypes. For example, morpho-anatomical mapping of brain anatomy across 26 mouse-ASD-genetic-models (147) has identified three neurosubtypes affecting distinct sets of brain regions with shared patterns across seemingly unrelated ASD mutations. The recent implementation of resting-fMRI in mice $(145,148,149)$ also offers the possibility to expand this approach to functional networks. Indeed, a previous study has demonstrated that 16p11.2 microdeletion comparably impairs iFC in both humans and mice (150).

\section{Conclusions}

Advances in neuroimaging and computational science, with evidence that ASD heterogeneity uniquely affects multiple domains and scales, have motivated neurosubtyping. Results from initial efforts illustrate the feasibility and potential utility of this approach. Yet, they also underscore current limitations, including the need for larger datasets, wider and deeper 
phenotyping, advanced analytical models that capture, with high replicability, the hybrid categorical and dimensional - nature of ASD heterogeneity. 


\section{Acknowledgments and Financial Disclosure}

This work was supported by grants from the National Institute of Mental Health (R01MH105506 and R01MH115363 to ADM and the 1R21MH116473-01A1 to AG), the Canadian Institutes of Health Research (postdoctoral fellowship MFE-158228 to SJH), the National Science Foundation (EEC-1707298 to JTV), the Singapore National Research Foundation (NRF) Fellowship (Class of 2017) to BTTY, the European Research Council (ERC; DISCONN; no. 802371 to AG), the Simons Foundation (SFARI 400101 to AG), and the Brain and Behavior Foundation (NARSAD; Independent Investigator Grant; no. 25861 to AG), SickKids Foundation (NI17-039 to BB), National Sciences and Engineering Research Council of Canada (Discovery1304413 to BB), Canadian Institutes of Health Research (FDN-154298 to BB), Azrieli Center for Autism Research, and the Canada Research Chairs program (to BB). The authors wish to thank Irene Droney, MSW for copyediting a latest version of the manuscript.

Dr. Di Martino receives royalties from the publication of the Italian version of the Social Responsiveness Scale —Child Version by Organization Speciali, Italy. All other authors report no biomedical financial interests, nor potential conflicts of interest. 


\section{REFERENCES}

1. Kapur S, Phillips AG, Insel TR (2012): Why has it taken so long for biological psychiatry to develop clinical tests and what to do about it? Mol Psychiatr. 17:1174.

2. Cuthbert BN, Insel TR (2013): Toward the future of psychiatric diagnosis: the seven pillars of RDoC. BMC Med. 11:126.

3. Feczko E, Miranda-Dominguez O, Marr M, Graham AM, Nigg JT, Fair DA (2019): The Heterogeneity Problem: Approaches to Identify Psychiatric Subtypes. Trends Cogn Sci. 23:584601 .

4. Marquand AF, Rezek I, Buitelaar J, Beckmann CF (2016): Understanding Heterogeneity in Clinical Cohorts Using Normative Models: Beyond Case-Control Studies. Biological Psychiatry. 80:552-561.

5. Bzdok D, Meyer-Lindenberg A (2018): Machine Learning for Precision Psychiatry: Opportunities and Challenges. Biol Psychiatry Cogn Neurosci Neuroimaging. 3:223-230.

6. Stephan KE, Bach DR, Fletcher PC, Flint J, Frank MJ, Friston KJ, et al. (2016): Charting the landscape of priority problems in psychiatry, part 1: classification and diagnosis. Lancet Psychiatry. 3:77-83.

7. Huys QJ, Maia TV, Frank MJ (2016): Computational psychiatry as a bridge from neuroscience to clinical applications. Nature neuroscience. 19:404.

8. Wolfers T, Floris DL, Dinga R, van Rooij D, Isakoglou C, Kia SM, et al. (2019): From pattern classification to stratification: towards conceptualizing the heterogeneity of Autism Spectrum Disorder. Neurosci Biobehav Rev. 104:240-254.

9. Ozonoff S, Heung K, Byrd R, Hansen R, Hertz-Picciotto I (2008): The onset of autism: patterns of symptom emergence in the first years of life. Autism Res. 1:320-328.

10. Grzadzinski R, Huerta M, Lord C (2013): DSM-5 and autism spectrum disorders (ASDs): an opportunity for identifying ASD subtypes. Mol Autism. 4:12-12.

11. Jeste SS, Geschwind DH (2014): Disentangling the heterogeneity of autism spectrum disorder through genetic findings. Nat Rev Neurol. 10:74-81.

12. Hansen SN, Schendel DE, Parner ET (2015): Explaining the increase in the prevalence of autism spectrum disorders: the proportion attributable to changes in reporting practices. JAMA Pediatr. 169:56-62.

13. Buckley PF, Miller BJ, Lehrer DS, Castle DJ (2009): Psychiatric comorbidities and schizophrenia. Schizophr Bull. 35:383-402.

14. Spoorthy MS, Chakrabarti S, Grover S (2019): Comorbidity of bipolar and anxiety disorders: An overview of trends in research. World J Psychiatry. 9:7-29.

15. Georgiades S, Szatmari P, Boyle M, Hanna S, Duku E, Zwaigenbaum L, et al. (2013): Investigating phenotypic heterogeneity in children with autism spectrum disorder: a factor mixture modeling approach. J Child Psychol Psychiatry. 54:206-215.

16. Gotham K, Brunwasser SM, Lord C (2015): Depressive and anxiety symptom trajectories from school age through young adulthood in samples with autism spectrum disorder and developmental delay. J Am Acad Child Adolesc Psychiatry. 54:369-376.e363.

17. Pickles A, Anderson DK, Lord C (2014): Heterogeneity and plasticity in the development of language: a 17-year follow-up of children referred early for possible autism. $J$ Child Psychol Psychiatry. 55:1354-1362.

18. Anderson DK, Lord C, Risi S, DiLavore PS, Shulman C, Thurm A, et al. (2007): Patterns of growth in verbal abilities among children with autism spectrum disorder. Journal of consulting and clinical psychology. 75:594. 
19. Charman T, Pickles A, Simonoff E, Chandler S, Loucas T, Baird G (2011): IQ in children with autism spectrum disorders: data from the Special Needs and Autism Project (SNAP). Psychol Med. 41:619-627.

20. Vargason T, Frye RE, McGuinness DL, Hahn J (2019): Clustering of co-occurring conditions in autism spectrum disorder during early childhood: A retrospective analysis of medical claims data. Autism Res.

21. Asperger H (1944): Die „Autistischen psychopathen” im kindesalter. Archiv für psychiatrie und nervenkrankheiten. 117:76-136.

22. Kanner L (1943): Autistic disturbances of affective contact. Nervous child. 2:217-250.

23. Boat TF, Wu JT, of Behavioral D, Sciences S, National Academies of Sciences E, Medicine (2015): Prevalence of autism spectrum disorder. Mental disorders and disabilities among lowincome children: National Academies Press (US).

24. Christensen DL, Braun KVN, Baio J, Bilder D, Charles J, Constantino JN, et al. (2018): Prevalence and characteristics of autism spectrum disorder among children aged 8 years - autism and developmental disabilities monitoring network, 11 sites, United States, 2012. MMWR Surveillance Summaries. 65:1.

25. Keyes KM, Susser E, Cheslack-Postava K, Fountain C, Liu K, Bearman PS (2011): Cohort effects explain the increase in autism diagnosis among children born from 1992 to 2003 in California. International journal of epidemiology. 41:495-503.

26. Shattuck PT (2006): The contribution of diagnostic substitution to the growing administrative prevalence of autism in US special education. Pediatrics. 117:1028-1037.

27. Rødgaard E-M, Jensen K, Vergnes J-N, Soulières I, Mottron L (2019): Temporal Changes in Effect Sizes of Studies Comparing Individuals With and Without Autism: A Meta-analysis. JAMA psychiatry. 76:1124-1132.

28. Szatmari P, Georgiades S, Duku E, Bennett TA, Bryson S, Fombonne E, et al. (2015): Developmental trajectories of symptom severity and adaptive functioning in an inception cohort of preschool children with autism spectrum disorder. JAMA Psychiatry. 72:276-283.

29. Fountain C, Winter AS, Bearman PS (2012): Six developmental trajectories characterize children with autism. Pediatrics. 129:e1112-1120.

30. Gotham K, Pickles A, Lord C (2012): Trajectories of autism severity in children using standardized ADOS scores. Pediatrics. 130:e1278-e1284.

31. Kim SH, Macari S, Koller J, Chawarska K (2016): Examining the phenotypic heterogeneity of early autism spectrum disorder: subtypes and short-term outcomes. J Child Psychol Psychiatry. 57:93-102.

32. Lord C, Bishop S, Anderson D (2015): Developmental trajectories as autism phenotypes. Am J Med Genet C Semin Med Genet. 169:198-208.

33. Magiati I, Tay XW, Howlin P (2014): Cognitive, language, social and behavioural outcomes in adults with autism spectrum disorders: a systematic review of longitudinal follow-up studies in adulthood. Clin Psychol Rev. 34:73-86.

34. Bacon EC, Dufek S, Schreibman L, Stahmer AC, Pierce K, Courchesne E (2014): Measuring Outcome in an Early Intervention Program for Toddlers with Autism Spectrum Disorder: Use of a Curriculum-Based Assessment. Autism Research and Treatment. 2014:9.

35. Betancur C (2011): Etiological heterogeneity in autism spectrum disorders: more than 100 genetic and genomic disorders and still counting. Brain Res. 1380:42-77. 
36. Insel T, Cuthbert B, Garvey M, Heinssen R, Pine DS, Quinn K, et al. (2010): Research domain criteria (RDoC): toward a new classification framework for research on mental disorders. Am J Psychiatry. 167:748-751.

37. Bilder RM, Sabb FW, Cannon TD, London ED, Jentsch JD, Parker DS, et al. (2009): Phenomics: the systematic study of phenotypes on a genome-wide scale. Neuroscience. 164:3042.

38. Feczko E, Balba NM, Miranda-Dominguez O, Cordova M, Karalunas SL, Irwin L, et al. (2018): Subtyping cognitive profiles in Autism Spectrum Disorder using a Functional Random Forest algorithm. NeuroImage. 172:674-688.

39. Van Dam NT, O'Connor D, Marcelle ET, Ho EJ, Cameron Craddock R, Tobe RH, et al. (2017): Data-Driven Phenotypic Categorization for Neurobiological Analyses: Beyond DSM-5 Labels. Biol Psychiatry. 81:484-494.

40. Leek JT, Storey JD (2007): Capturing heterogeneity in gene expression studies by surrogate variable analysis. PLoS Genet. 3:1724-1735.

41. Haufe S, Meinecke F, Gorgen K, Dahne S, Haynes JD, Blankertz B, et al. (2014): On the interpretation of weight vectors of linear models in multivariate neuroimaging. Neuroimage. 87:96-110.

42. Varoquaux G, Thirion B (2014): How machine learning is shaping cognitive neuroimaging. Gigascience. 3:28.

43. Jimura K, Poldrack RA (2012): Analyses of regional-average activation and multivoxel pattern information tell complementary stories. Neuropsychologia. 50:544-552.

44. Wing L, Gould J (1979): Severe impairments of social interaction and associated abnormalities in children: epidemiology and classification. J Autism Dev Disord. 9:11-29.

45. Bell CC (1994): DSM-IV: diagnostic and statistical manual of mental disorders. Jama. 272:828-829.

46. Lord C, Jones RM (2012): Annual research review: re-thinking the classification of autism spectrum disorders. J Child Psychol Psychiatry. 53:490-509.

47. Association AP (2013): Diagnostic and statistical manual of mental disorders (DSM-5®). American Psychiatric Pub.

48. Reed GM (2010): Toward ICD-11: Improving the clinical utility of WHO's International Classification of mental disorders. Professional Psychology: Research and Practice. 41:457.

49. Tripoliti EE, Papadopoulos TG, Karanasiou GS, Naka KK, Fotiadis DI (2017): Heart Failure: Diagnosis, Severity Estimation and Prediction of Adverse Events Through Machine Learning Techniques. Comput Struct Biotechnol J. 15:26-47.

50. Sandin S, Lichtenstein P, Kuja-Halkola R, Hultman C, Larsson H, Reichenberg A (2017): The Heritability of Autism Spectrum Disorder. JAMA. 318:1182-1184.

51. Grove J, Ripke S, Als TD, Mattheisen M, Walters RK, Won H, et al. (2019): Identification of common genetic risk variants for autism spectrum disorder. Nat Genet. 51:431-444.

52. Buxbaum JD (2009): Multiple rare variants in the etiology of autism spectrum disorders. Dialogues Clin Neurosci. 11:35-43.

53. pfeliciano@simonsfoundation.org SCEa, Consortium S (2018): SPARK: A US Cohort of 50,000 Families to Accelerate Autism Research. Neuron. 97:488-493.

54. Sanders SJ, He X, Willsey AJ, Ercan-Sencicek AG, Samocha KE, Cicek AE, et al. (2015): Insights into autism spectrum disorder genomic architecture and biology from 71 risk loci. Neuron. 87:1215-1233. 
55. Stessman HA, Bernier R, Eichler EE (2014): A genotype-first approach to defining the subtypes of a complex disease. Cell. 156:872-877.

56. Simons Vip C (2012): Simons Variation in Individuals Project (Simons VIP): a geneticsfirst approach to studying autism spectrum and related neurodevelopmental disorders. Neuron. 73:1063-1067.

57. Abrahams BS, Geschwind DH (2008): Advances in autism genetics: on the threshold of a new neurobiology. Nat Rev Genet. 9:341-355.

58. Pantelis PC, Kennedy DP (2017): Deconstructing atypical eye gaze perception in autism spectrum disorder. Sci Rep. 7:14990.

59. Picci G, Gotts SJ, Scherf KS (2016): A theoretical rut: revisiting and critically evaluating the generalized under/over-connectivity hypothesis of autism. Dev Sci. 19:524-549.

60. Easson AK, Fatima Z, McIntosh AR (2018): Functional connectivity-based subtypes of individuals with and without autism spectrum disorder. Network Neuroscience. 3:344-362.

61. Duffy FH, Als H (2019): Autism, spectrum or clusters? An EEG coherence study. BMC Neurol. 19:27.

62. Chen H, Uddin LQ, Guo X, Wang J, Wang R, Wang X, et al. (2019): Parsing brain structural heterogeneity in males with autism spectrum disorder reveals distinct clinical subtypes. Hum Brain Mapp. 40:628-637.

63. Jao Keehn RJ, Nair S, Pueschel EB, Linke AC, Fishman I, Muller RA (2018): Atypical Local and Distal Patterns of Occipito-frontal Functional Connectivity are Related to Symptom Severity in Autism. Cereb Cortex.

64. Hrdlicka M, Dudova I, Beranova I, Lisy J, Belsan T, Neuwirth J, et al. (2005): Subtypes of autism by cluster analysis based on structural MRI data. Eur Child Adolesc Psychiatry. 14:138144.

65. Hong S-J, Valk SL, Di Martino A, Milham MP, Bernhardt BC (2017): Multidimensional Neuroanatomical Subtyping of Autism Spectrum Disorder. Cerebral Cortex.1-11.

66. Bethlehem RAI, Seidlitz J, Romero-Garcia R, Lombardo MV (2018): Using normative age modelling to isolate subsets of individuals with autism expressing highly age-atypical cortical thickness features. bioRxiv.252593.

67. Stefanik L, Erdman L, Ameis SH, Foussias G, Mulsant BH, Behdinan T, et al. (2018): Brain-Behavior Participant Similarity Networks Among Youth and Emerging Adults with Schizophrenia Spectrum, Autism Spectrum, or Bipolar Disorder and Matched Controls. Neuropsychopharmacol. 43:1180-1188.

68. Kernbach JM, Satterthwaite TD, Bassett DS, Smallwood J, Margulies D, Krall S, et al. (2018): Shared endo-phenotypes of default mode dsfunction in attention deficit/hyperactivity disorder and autism spectrum disorder. Transl Psychiatry. 8:133.

69. Lefebvre A, Delorme R, Delanoe C, Amsellem F, Beggiato A, Germanaud D, et al. (2018): Alpha Waves as a Neuromarker of Autism Spectrum Disorder: The Challenge of Reproducibility and Heterogeneity. Front Neurosci-Switz. 12.

70. Zabihi M, Oldehinkel M, Wolfers T, Frouin V, Goyard D, Loth E, et al. (2019): Dissecting the Heterogeneous Cortical Anatomy of Autism Spectrum Disorder Using Normative Models. Biological psychiatry Cognitive neuroscience and neuroimaging. 4:567-578.

71. Tang S, Sun N, Floris DL, Zhang X, Di Martino A, Yeo BTT (2019): Reconciling Dimensional and Categorical Models of Autism Heterogeneity: a Brain Connectomics \& Behavioral Study. Biological Psychiatry. 
72. Lombardo MV, Lai MC, Baron-Cohen S (2019): Big data approaches to decomposing heterogeneity across the autism spectrum. Mol Psychiatry.

73. Insel TR (2014): The NIMH Research Domain Criteria (RDoC) Project: precision medicine for psychiatry. Am J Psychiatry. 171:395-397.

74. Milham MP, Craddock RC, Son JJ, Fleischmann M, Clucas J, Xu H, et al. (2018): Assessment of the impact of shared brain imaging data on the scientific literature. Nat Commun. 9:2818.

75. Di Martino A, Yan CG, Li Q, Denio E, Castellanos FX, Alaerts K, et al. (2014): The autism brain imaging data exchange: towards a large-scale evaluation of the intrinsic brain architecture in autism. Mol Psychiatry. 19:659-667.

76. Di Martino A, O'Connor D, Chen B, Alaerts K, Anderson JS, Assaf M, et al. (2017): Enhancing studies of the connectome in autism using the autism brain imaging data exchange II. Sci Data. 4:170010.

77. Loth E, Charman T, Mason L, Tillmann J, Jones EJH, Wooldridge C, et al. (2017): The EU-AIMS Longitudinal European Autism Project (LEAP): design and methodologies to identify and validate stratification biomarkers for autism spectrum disorders. Mol Autism. 8:24.

78. Kooijman MN, Kruithof CJ, van Duijn CM, Duijts L, Franco OH, van IMH, et al. (2016): The Generation R Study: design and cohort update 2017. Eur J Epidemiol. 31:1243-1264.

79. Hall D, Huerta MF, McAuliffe MJ, Farber GK (2012): Sharing heterogeneous data: the national database for autism research. Neuroinformatics. 10:331-339.

80. Nooner KB, Colcombe SJ, Tobe RH, Mennes M, Benedict MM, Moreno AL, et al. (2012): The NKI-Rockland Sample: A Model for Accelerating the Pace of Discovery Science in Psychiatry. Front Neurosci. 6:152.

81. Al-Jawahiri R, Milne E (2017): Resources available for autism research in the big data era: a systematic review. PeerJ. 5:e2880.

82. Casanova MF, El-Baz AS, Kamat SS, Dombroski BA, Khalifa F, Elnakib A, et al. (2013): Focal cortical dysplasias in autism spectrum disorders. Acta Neuropathol Commun 1:67.

83. Avino TA, Hutsler JJ (2010): Abnormal cell patterning at the cortical gray-white matter boundary in autism spectrum disorders. Brain Res. 1360:138-146.

84. Wegiel J, Kuchna I, Nowicki K, Imaki H, Wegiel J, Marchi E, et al. (2010): The neuropathology of autism: defects of neurogenesis and neuronal migration, and dysplastic changes. Acta Neuropathol. 119:755-770.

85. Duffy FH, Als H (2012): A stable pattern of EEG spectral coherence distinguishes children with autism from neuro-typical controls - a large case control study. BMC Med. 10:64.

86. Saeys Y, Inza I, Larranaga P (2007): A review of feature selection techniques in bioinformatics. Bioinformatics. 23:2507-2517.

87. Dy JG, Brodley CE (2004): Feature selection for unsupervised learning. Journal of machine learning research. 5:845-889.

88. Hughes G (1968): On the mean accuracy of statistical pattern recognizers. IEEE transactions on information theory. 14:55-63.

89. Wang B, Mezlini AM, Demir F, Fiume M, Tu Z, Brudno M, et al. (2014): Similarity network fusion for aggregating data types on a genomic scale. Nat Methods. 11:333-337.

90. Shen C, Vogelstein JT, Priebe CE (2017): Manifold matching using shortest-path distance and joint neighborhood selection. Pattern Recognition Letters. 92:41-48.

91. Pai S, Bader GD (2018): Patient Similarity Networks for Precision Medicine. J Mol Biol. 430:2924-2938. 
92. Ruan P, Wang Y, Shen R, Wang S (2019): Using association signal annotations to boost similarity network fusion. Bioinformatics.

93. Xu C, Tao D, Xu C (2013): A survey on multi-view learning. arXiv preprint arXiv: 13045634.

94. Lock EF, Hoadley KA, Marron JS, Nobel AB (2013): Joint and Individual Variation Explained (Jive) for Integrated Analysis of Multiple Data Types. Ann Appl Stat. 7:523-542.

95. Zhao Y, Klein A, Castellanos FX, Milham MP (2019): Brain Age Prediction: Cortical and Subcortical Shape Covariation in the Developing Human Brain. bioRxiv.570333.

96. Smith SM, Nichols TE, Vidaurre D, Winkler AM, Behrens TE, Glasser MF, et al. (2015): A positive-negative mode of population covariation links brain connectivity, demographics and behavior. Nat Neurosci. 18:1565-1567.

97. Drysdale AT, Grosenick L, Downar J, Dunlop K, Mansouri F, Meng Y, et al. (2017): Resting-state connectivity biomarkers define neurophysiological subtypes of depression. Nature medicine. 23:28.

98. Kaufman S, Rosset S, Perlich C, Stitelman O (2012): Leakage in data mining: Formulation, detection, and avoidance. ACM Transactions on Knowledge Discovery from Data (TKDD). 6:15.

99. Castellanos FX, Di Martino A, Craddock RC, Mehta AD, Milham MP (2013): Clinical applications of the functional connectome. Neuroimage. 80:527-540.

100. Zuo XN, Xu T, Milham MP (2019): Harnessing reliability for neuroscience research. Nat Hum Behav.

101. Ai L, Craddock RC, Tottenham N, Colcombe S, Milham M, Franco AR (2019): Reliability and Reproducibility of T1-weighted images: comparing MPRAGE and Prospective Motion Correction with Volumetric Navigators. bioRxiv.666289.

102. Iscan Z, Jin TB, Kendrick A, Szeglin B, Lu H, Trivedi M, et al. (2015): Test-retest reliability of freesurfer measurements within and between sites: Effects of visual approval process. Human Brain Mapping. 36:3472-3485.

103. Madan CR, Kensinger EA (2017): Test-retest reliability of brain morphology estimates. Brain Inform. 4:107-121.

104. O'Connor D, Potler NV, Kovacs M, Xu T, Ai L, Pellman J, et al. (2017): The Healthy Brain Network Serial Scanning Initiative: a resource for evaluating inter-individual differences and their reliabilities across scan conditions and sessions. Gigascience. 6.

105. Elliott ML, Knodt AR, Cooke M, Kim MJ, Melzer TR, Keenan R, et al. (2019): General functional connectivity: Shared features of resting-state and task fMRI drive reliable and heritable individual differences in functional brain networks. Neuroimage. 189:516-532.

106. Gosain A, Dahiya S (2016): Performance analysis of various fuzzy clustering algorithms: a review. Procedia Computer Science. 79:100-111.

107. Marquand AF, Wolfers T, Mennes M, Buitelaar J, Beckmann CF (2016): Beyond Lumping and Splitting: A Review of Computational Approaches for Stratifying Psychiatric Disorders. Biol Psychiatry Cogn Neurosci Neuroimaging. 1:433-447.

108. Liu Y, Li Z, Xiong H, Gao X, Wu J (2010): Understanding of internal clustering validation measures. 2010 IEEE International Conference on Data Mining: IEEE, pp 911-916.

109. Priebe CE, Park Y, Vogelstein JT, Conroy JM, Lyzinski V, Tang M, et al. (2019): On a two-truths phenomenon in spectral graph clustering. Proc Natl Acad Sci U S A. 116:5995-6000.

110. Zhang X, Mormino EC, Sun N, Sperling RA, Sabuncu MR, Yeo BT, et al. (2016): Bayesian model reveals latent atrophy factors with dissociable cognitive trajectories in Alzheimer's disease. Proc Natl Acad Sci U S A. 113:E6535-E6544. 
111. Thompson WK, Hallmayer J, O'Hara R, Initiative AsDN (2011): Design considerations for characterizing psychiatric trajectories across the lifespan: application to effects of APOE- $\varepsilon 4$ on cerebral cortical thickness in Alzheimer's disease. Am J Psychiat. 168:894-903.

112. Dean DC, Dirks H, O’Muircheartaigh J, Walker L, Jerskey BA, Lehman K, et al. (2014): Pediatric neuroimaging using magnetic resonance imaging during non-sedated sleep. Pediatric radiology. 44:64-72.

113. Manning JH, Courchesne E, Fox PT (2013): Intrinsic connectivity network mapping in young children during natural sleep. Neuroimage. 83:288-293.

114. Bolton TA, Jochaut D, Giraud AL, Van De Ville D (2018): Brain dynamics in ASD during movie-watching show idiosyncratic functional integration and segregation. Human brain mapping. 39:2391-2404.

115. Vanderwal T, Kelly C, Eilbott J, Mayes LC, Castellanos FX (2015): Inscapes: A movie paradigm to improve compliance in functional magnetic resonance imaging. Neuroimage. 122:222-232.

116. Nordahl CW, Mello M, Shen AM, Shen MD, Vismara LA, Li D, et al. (2016): Methods for acquiring MRI data in children with autism spectrum disorder and intellectual impairment without the use of sedation. Journal of neurodevelopmental disorders. 8:20.

117. Dosenbach NUF, Koller JM, Earl EA, Miranda-Dominguez O, Klein RL, Van AN, et al. (2017): Real-time motion analytics during brain MRI improve data quality and reduce costs. Neuroimage. 161:80-93.

118. Tisdall MD, Reuter M, Qureshi A, Buckner RL, Fischl B, van der Kouwe AJW (2016): Prospective motion correction with volumetric navigators (vNavs) reduces the bias and variance in brain morphometry induced by subject motion. Neuroimage. 127:11-22.

119. Loomes R, Hull L, Mandy WPL (2017): What is the male-to-female ratio in autism spectrum disorder? A systematic review and meta-analysis. Journal of the American Academy of Child \& Adolescent Psychiatry. 56:466-474.

120. Lai MC, Lombardo MV, Auyeung B, Chakrabarti B, Baron-Cohen S (2015): Sex/gender differences and autism: setting the scene for future research. J Am Acad Child Adolesc Psychiatry. 54:11-24.

121. Floris DL, Lai MC, Nath T, Milham MP, Di Martino A (2018): Network-specific sex differentiation of intrinsic brain function in males with autism. Mol Autism. 9:17.

122. Irimia A, Torgerson CM, Jacokes ZJ, Van Horn JD (2017): The connectomes of males and females with autism spectrum disorder have significantly different white matter connectivity densities. Scientific reports. 7:46401.

123. Button KS, Ioannidis JP, Mokrysz C, Nosek BA, Flint J, Robinson ES, et al. (2013): Power failure: why small sample size undermines the reliability of neuroscience. Nat Rev Neurosci. 14:365-376.

124. Baker M (2016): 1,500 scientists lift the lid on reproducibility. Nature. 533:452-454.

125. Breiman L (1996): Bagging Predictors. Machine Learning. 24:123-140.

126. Nikolaidis A, Solon Heinsfeld A, Xu T, Bellec P, Vogelstein J, Milham M (2019): Bagging Improves Reproducibility of Functional Parcellation of the Human Brain. bioRxiv.343392.

127. Kelly C, Toro R, Di Martino A, Cox CL, Bellec P, Castellanos FX, et al. (2012): A convergent functional architecture of the insula emerges across imaging modalities. Neuroimage. 61:1129-1142.

128. Bellec P, Rosa-Neto P, Lyttelton OC, Benali H, Evans AC (2010): Multi-level bootstrap analysis of stable clusters in resting-state fMRI. Neuroimage. 51:1126-1139. 
129. Martinez-Murcia FJ, Lai MC, Gorriz JM, Ramirez J, Young AM, Deoni SC, et al. (2017): On the brain structure heterogeneity of autism: Parsing out acquisition site effects with significance-weighted principal component analysis. Hum Brain Mapp. 38:1208-1223.

130. Leek JT, Johnson WE, Parker HS, Jaffe AE, Storey JD (2012): The sva package for removing batch effects and other unwanted variation in high-throughput experiments. Bioinformatics. 28:882-883.

131. Nielson DM, Pereira F, Zheng CY, Migineishvili N, Lee JA, Thomas AG, et al. (2018): Detecting and harmonizing scanner differences in the ABCD study - annual release 1.0. bioRxiv.309260.

132. Lai M, Lombardo M, Baron-Cohen S Autism. Lancet [Internet]. 2014 [cited 2016 Nov 18]; 383 (9920): 896-910.

133. Leekam S (2016): Social cognitive impairment and autism: what are we trying to explain? Philosophical Transactions of the Royal Society B: Biological Sciences. 371:20150082.

134. Herrington JD, Miller JS, Pandey J, Schultz RT (2016): Anxiety and social deficits have distinct relationships with amygdala function in autism spectrum disorder. Social cognitive and affective neuroscience. 11:907-914.

135. Bennett RH, Somandepalli K, Roy AK, Di Martino A (2017): The Neural Correlates of Emotional Lability in Children with Autism Spectrum Disorder. Brain Connect. 7:281-288.

136. Chantiluke K, Christakou A, Murphy CM, Giampietro V, Daly EM, Ecker C, et al. (2014): Disorder-specific functional abnormalities during temporal discounting in youth with Attention Deficit Hyperactivity Disorder (ADHD), Autism and comorbid ADHD and Autism. Psychiatry Res. 223:113-120.

137. Di Martino A, Zuo X-N, Kelly C, Grzadzinski R, Mennes M, Schvarcz A, et al. (2013): Shared and distinct intrinsic functional network centrality in autism and attentiondeficit/hyperactivity disorder. Biological psychiatry. 74:623-632.

138. Courchesne E, Pierce K (2005): Why the frontal cortex in autism might be talking only to itself: local over-connectivity but long-distance disconnection. Current Opinion in Neurobiology. 15:225-230.

139. Smith RX, Jann K, Dapretto M, Wang DJJ (2018): Imbalance of Functional Connectivity and Temporal Entropy in Resting-State Networks in Autism Spectrum Disorder: A Machine Learning Approach. Frontiers in neuroscience. 12:869.

140. Cerliani L, Mennes M, Thomas RM, Di Martino A, Thioux M, Keysers C (2015): Increased functional connectivity between subcortical and cortical resting-state networks in autism spectrum disorder. JAMA psychiatry. 72:767-777.

141. Hahamy A, Behrmann M, Malach R (2015): The idiosyncratic brain: distortion of spontaneous connectivity patterns in autism spectrum disorder. Nat Neurosci. 18:302-309.

142. Hong SJ, de Wael RV, Bethlehem RAI, Lariviere S, Paquola C, Valk SL, et al. (2019): Atypical functional connectome hierarchy in autism. Nat Commun. 10:1022.

143. Zhou Y, Sharma J, Ke Q, Landman R, Yuan J, Chen H, et al. (2019): Atypical behaviour and connectivity in SHANK3-mutant macaques. Nature. 570:326-331.

144. Liska A, Gozzi A (2016): Can mouse imaging studies bring order to autism connectivity chaos? Front Neurosci-Switz. 10:484.

145. Gozzi A, Schwarz AJ (2016): Large-scale functional connectivity networks in the rodent brain. Neuroimage. 127:496-509. 
146. Bertero A, Liska A, Pagani M, Parolisi R, Masferrer ME, Gritti M, et al. (2018): Autismassociated 16p11.2 microdeletion impairs prefrontal functional connectivity in mouse and human. Brain. 141:2055-2065.

147. Ellegood J, Anagnostou E, Babineau BA, Crawley JN, Lin L, Genestine M, et al. (2015): Clustering autism: using neuroanatomical differences in 26 mouse models to gain insight into the heterogeneity. Mol Psychiatr. 20:118-125.

148. Sforazzini F, Schwarz AJ, Galbusera A, Bifone A, Gozzi A (2014): Distributed BOLD and CBV-weighted resting-state networks in the mouse brain. Neuroimage. 87:403-415.

149. Liska A, Galbusera A, Schwarz AJ, Gozzi A (2015): Functional connectivity hubs of the mouse brain. Neuroimage. 115:281-291.

150. Bertero A, Liska A, David G, Galbusera A, Pasqualetti M, Gozzi A (2015): Frontal hypoconnectivity in the 16p11.2 microdeletion autism model. Neuroscience 2015: USA.

151. Dosenbach NU, Nardos B, Cohen AL, Fair DA, Power JD, Church JA, et al. (2010): Prediction of individual brain maturity using fMRI. Science. 329:1358-1361.

152. Schaefer A, Kong R, Gordon EM, Laumann TO, Zuo XN, Holmes AJ, et al. (2018): LocalGlobal Parcellation of the Human Cerebral Cortex from Intrinsic Functional Connectivity MRI. Cereb Cortex. 28:3095-3114.

153. Alexander LM, Escalera J, Ai L, Andreotti C, Febre K, Mangone A, et al. (2017): An open resource for transdiagnostic research in pediatric mental health and learning disorders. bioRxiv.

154. Ameis SH, Lerch JP, Taylor MJ, Lee W, Viviano JD, Pipitone J, et al. (2016): A Diffusion Tensor Imaging Study in Children With ADHD, Autism Spectrum Disorder, OCD, and Matched Controls: Distinct and Non-Distinct White Matter Disruption and Dimensional Brain-Behavior Relationships. Am J Psychiatry. 173:1213-1222. 


\section{FIGURE CAPTIONS}

Figure 1. Minimally overlapping neurosubtyping research designs in Autism Spectrum Disorder (ASD). Research designs across current ASD neurosubtyping studies are displayed in matrix form. Columns denote the feature domains used for a given subtyping algorithm. Rows denote the feature domains used for validation. The nested pie charts present further information about variability of subtyping approaches in terms of employed algorithms (outer pie layer; blue for clustering, green for latent factor analysis and orange for normative modeling) and samples (inner pie layer - indicated by the letter $a$ for ASD-only, $b$ for ASD+Neurotypicals and $c$ for Transdiagnostic cohorts). The size of the pie chart refers to the number of existing studies at a given feature domain junction (matrix index). Abbreviation: NT: Neurotypicals, s-MRI: structural MRI, d-MRI: diffusion-based MRI, R-fMRI: resting-state fMRI, EEG: electroencephalogram

FIGURE 2. Key methodological steps in neurosubtyping. A) Selection strategies for diagnostic samples may focus on neurosubtyping within the autism spectrum disorder (ASD) or extend it to neurotypicals (NT) and/or other psychiatric diagnoses. Including NT can account for variance in the neurotypical population, while including other psychiatric conditions allows to examine the extent to which neurosubtypes are specific to a given diagnosis. B) Several steps exist for feature selection and processing. Feature selection (whether in the brain structural or functional domain) may be based on a priori knowledge or on quantitative approaches (86). Critical steps for feature processing include dimensionality reduction, data harmonization, and multimodal feature combination. C) The current ASD neurosubtyping literature comprises clustering-based analysis, latent factor analysis and normative modeling. See TABLE 1 for details. D) Primary strategies for validating neurosubtyping results. See TABLE 1 for details. Abbreviations: ADI-R: Autism Diagnostic Interview-Revised; ADOS: Autism Diagnostic Observation Schedule; BOLD: bloodoxygen-level-dependent; EEG: electroencephalography; GMV: gray matter volume; iFC: intrinsic functional connectivity; PCA; principal component analysis; ND: neurodevelopmental disorders; NMF: non-negative matrix factorization; CNV: copy number variation; VBM: voxelbased morphometry. 



\begin{tabular}{|c|c|c|c|c|c|c|c|c|c|}
\hline \multirow[b]{2}{*}{ Study } & \multicolumn{4}{|c|}{ Sample $^{a}$} & \multicolumn{3}{|c|}{ Approach } & \multicolumn{2}{|r|}{ Results } \\
\hline & $\begin{array}{l}\text { Data } \\
\text { source }\end{array}$ & $\mathrm{N}$ & $\begin{array}{c}\text { Age } \\
\text { range } \\
\text { years }\end{array}$ & $\begin{array}{l}\text { Males } \\
\text { N (\%) }\end{array}$ & Subtyping & Feature(s) & Validation $^{\mathbf{c}}$ & $\begin{array}{l}\text { NS } \\
(\#)\end{array}$ & Highlights \\
\hline$(60)$ & Abide I & $\begin{array}{c}145 \text { ASD } \\
121 \mathrm{NT}\end{array}$ & $7-39$ & All males & \multirow{3}{*}{$\begin{array}{l}\text { Clustering } \\
\text { (K-means) }\end{array}$} & $\begin{array}{l}R \text { - } f M R I \\
\text { iFC } 160 \text { cortical } \\
\text { ROI }^{\mathrm{j}}\end{array}$ & SRS, IQ, ADOS & 2 & $\begin{array}{c}\text { NS1 (59\% ASD, 45\% NT), NS2 (41\% ASD, 55\% NT). } \\
\text { NS2 had lower }(\downarrow) \text { iFC between networks \& greater ( } \uparrow \text { ) } \\
\text { iFC within networks vs. NS1; NSs did not differ in } \\
\text { behavior, demographics, IQ, scan performance nor } \\
\text { parameters. PLS brain-behavior analyses showed iFC } \\
\text { correlations with a combination of symptom scores } \\
\text { unique to each NS. }\end{array}$ \\
\hline$(62)$ & Abide I, II & 356 ASD & $5-35$ & All males & & $\begin{array}{l}\text { sMRI; } \\
\text { whole brain } \\
\text { VBM }\end{array}$ & ADOS, iFC & 3 & $\begin{array}{l}\text { NS1 (18\%): } \downarrow \text { prefrontal GMV, NS2 (53\%): } \uparrow \text { temporal } \\
\& \downarrow \text { prefrontal \& occipital GMV, NS3 (29\%): } \uparrow \text { GMV } \\
\text { temporal vs. NT. ADOS scores were different between } \\
\text { NSs. iFC in fronto-parietal network differed between } \\
\text { NS1 and NS3. NSs improved supervised classification. }\end{array}$ \\
\hline$(63)$ & $\begin{array}{l}\text { Lab } \\
\text { specific }\end{array}$ & $57 \mathrm{ASD}$ & $9-18$ & $47(82)$ & & $\begin{array}{l}R-f M R I \\
\text { occipital to } \\
\text { frontal pole } \\
\text { cortex iFC }\end{array}$ & $\begin{array}{l}\text { IQ, ADI-R, } \\
\text { ADOS, } \\
\text { comorbidities, } \\
\text { medication use, } \\
\text { age, sex }\end{array}$ & 2 & $\begin{array}{l}\text { Post-hoc clustering of iFC in ROI identified by group } \\
\text { mean. NSs had opposite iFC patterns and did not differ } \\
\text { in clinical and demographic metrics. }\end{array}$ \\
\hline$(61)$ & $\begin{array}{l}\text { Lab } \\
\text { specific }\end{array}$ & 430 ASD & $2-12$ & $361(84)$ & \multirow{3}{*}{$\begin{array}{l}\text { Clustering } \\
\text { (hierarchical } \\
\text { and K- } \\
\text { means) }\end{array}$} & $\begin{array}{l}E E G \\
40 \text { coherence } \\
\text { factors }\end{array}$ & NA & 2 & $\begin{array}{c}\text { NS1 } 1=39 \% \text {; NS2 }=61 \% .19 \text { of the } 40 \text { EEG features } \\
\text { discriminated NS1 ( } \uparrow \text { coherence in } 7 \text { factors out of } 40 \text {; } \downarrow \\
\text { in } 12 \text { out } 40 \text { ) vs. NS2 (opposite patterns with NS1) and } \\
\text { both NSs } v \text {. NT. NSs did not differ for age nor sex. }\end{array}$ \\
\hline$(65)$ & Abide I & 107 ASD & $7-50$ & All males & & $\begin{array}{c}s M R I ; \mathrm{CT}, \mathrm{SA}, \\
\text { IC, GD }\end{array}$ & ADOS, iFC & 3 & $\begin{array}{l}\text { NS1: } \uparrow \text { CT, SA and TB; NS2: } \downarrow \text { CT, GD; NS3: } \uparrow \text { GD. } \\
\text { Distinct ADOS and iFC load across NSs. NSs improved } \\
\text { supervised ADOS prediction above NS blind approach. }\end{array}$ \\
\hline$(64)$ & $\begin{array}{l}\text { Lab } \\
\text { specific }\end{array}$ & $64 \mathrm{ASD}$ & $9 \pm 6$ & $52(81)$ & & $\begin{array}{l}s M R I ; \text { 2D-slice } \\
\mathrm{CT} \text {, volumes in } \\
6 \mathrm{RO}^{j}\end{array}$ & $\begin{array}{l}\text { EEG profile, } \\
\text { epilepsy, medical } \\
\text { history, CARS }\end{array}$ & 4 & $\begin{array}{l}\text { NS1 (28\%; } \uparrow \text { CC); NS2 (52\%; } \uparrow \text { Amygdala and } \\
\text { Hippocampus), NS3 (14\%; } \uparrow \text { NC and } \downarrow \text { Hippocampus); } \\
\text { NS4 (6\%; } \downarrow \text { CC, Amygdala, NC). NSs did not differ by } \\
\text { age, IQ, nor severity but differed in ROI atypicalities, } \\
\text { pregnancy order, psychomotor early delay (NS4>NS2) }\end{array}$ \\
\hline
\end{tabular}




\begin{tabular}{|c|c|c|c|c|c|c|c|c|c|}
\hline (67) & $\begin{array}{c}\text { Lab } \\
\text { specific }\end{array}$ & $\begin{array}{l}38 \mathrm{ASD} \\
34 \mathrm{BD} \\
51 \mathrm{SSD} \\
51 \mathrm{NT}\end{array}$ & $16-35$ & $\begin{array}{l}26(76) \mathrm{ASD} \\
19(56) \mathrm{BD} \\
32(63) \mathrm{SSD} \\
24(47) \mathrm{NT}\end{array}$ & $\begin{array}{l}\text { Spectral } \\
\text { clustering } \\
\text { (SNF) }\end{array}$ & $\begin{array}{l}\text { sMRI; } \\
\text { demographics, } \\
\text { cognition } \\
\text { CT, subcortical } \\
\text { volume, DTI- } \\
\text { FA, MD; }\end{array}$ & $\begin{array}{l}\text { Cognitive and } \\
\text { emotion test } \\
\text { scores, CT-based } \\
\text { global efficiency }\end{array}$ & 4 & $\begin{array}{l}\text { NS1 (80\% ASD followed by SSD and BD; } \uparrow \text { SCV }, \downarrow \\
\text { FA, } \uparrow \text { CT), NS2 (64\% SSD and minor distribution of } \\
\text { other diagnoses; } \downarrow \text { SCV, } \downarrow \text { FA, } \uparrow \text { CT), NS3 (46\% NT } \\
\text { and } \sim 20 \% \text { each of the other; } \downarrow \text { SCV, } \downarrow \text { FA, } \downarrow \text { CT), NS4 } \\
\text { (similar proportion across diagnoses; } \uparrow \text { SCV, } \uparrow \text { FA). }\end{array}$ \\
\hline (68) & $\begin{array}{l}\text { Abide I, } \\
\text { ADHD- } \\
200\end{array}$ & $\begin{array}{l}369 \text { ASD } \\
284 \\
\text { ADHD } \\
752 \mathrm{NT}^{d}\end{array}$ & $7-21$ & All males & LFA $^{\mathrm{g}}$ & $\begin{array}{c}\quad R-f M R I \\
\text { iFC of } 21 \text { ROI } \\
\text { in DN, SN, DA }\end{array}$ & $\begin{array}{l}\text { Diagnostic } \\
\text { labels, symptom } \\
\text { questionnaires } \\
\text { (unspecified) }\end{array}$ & 3 & $\begin{array}{c}\text { NS1= } 1 \text { DN-DAN, 'medium” DN-SN, } \downarrow \text { intra-DN and } \\
\text { intra-DAN iFC and positive association with ADHD. } \\
\text { NS2 }=\downarrow \text { DN-DAN and DN-SN, associated to ASD } \\
\text { diagnosis, language and IQ. NS3: } \downarrow \text { DN-DAN. with no } \\
\text { behavioral associations. }\end{array}$ \\
\hline (71) & $\begin{array}{l}\text { Abide II, } \\
\text { Gendaar }\end{array}$ & $\begin{array}{c}306 \\
\mathrm{ASD}^{e}\end{array}$ & $\begin{array}{c}15 \pm 6 / \mathrm{gr} \\
\text { oup }\end{array}$ & $236(77)$ & LFA $^{g}$ & $\begin{array}{c}R-f M R I \\
418 \text { cortical }+ \\
\text { subcortical } \\
\text { iFC }^{m}\end{array}$ & $\begin{array}{l}\text { Multiple clinical } \\
\text { and } \\
\text { demographics }\end{array}$ & 3 & $\begin{array}{c}\text { NSs had dissociable whole-brain hypo/hyper iFC, and } \\
\text { shared atypical iFC in DN. Individuals expressed } \\
\text { multiple NSs at different degrees. NS1 associated with } \downarrow \\
\text { FC (DAN, SM, VN) and } \uparrow \text { FC (DN, CO) in ASD and } \\
\text { with symptom severity, NS2 with opposite patterns of } \\
\text { FC (compared to NS1) and with comorbid symptoms. } \\
\text { NS3 (complex mixture of } \uparrow \text { and } \downarrow \text { FC) preferentially } \\
\text { expressed in older males. }\end{array}$ \\
\hline (70) & $\begin{array}{l}\text { Eu-Aims } \\
\text { leap }\end{array}$ & $\begin{array}{l}321 \mathrm{ASD} \\
206 \mathrm{NT}\end{array}$ & $6-31$ & $\begin{array}{l}232(72) \\
\text { ASD } \\
127(62) \mathrm{NT}\end{array}$ & $\mathrm{NM}^{\mathrm{h}}$ & $\begin{array}{l}\quad s M R I \\
\text { age-and sex- } \\
\text { related CT, SA }\end{array}$ & $\begin{array}{l}\text { ADOS, } \\
\text { ADI-R, }\end{array}$ & 2 & $\begin{array}{l}28 \% \text { of the ASD cohort had regional age-related CT } \\
\text { deviations from the normative curve } v \text { s. } 19 \% \text { in NT. } \uparrow \\
\text { deviation in ASD vs NT. CT deviation associated to } \\
\text { RRB severity in females. Common case-control } \\
\text { comparisons yielded minimal regional differences in } \\
\text { contrast to those with the outlier subgroup. }\end{array}$ \\
\hline (66) & Abide I, II & $\begin{array}{c}942 \\
\mathrm{ASD}^{f}\end{array}$ & $6-20$ & $754(80)$ & & $\begin{array}{l}\quad s M R \mathrm{I} \\
\text { age-related } \mathrm{CT}\end{array}$ & NA & 2 & $\begin{array}{c}\text { 7-10\% of ASD cohort have age-related CT deviance ( }>2 \\
\text { w-score). Case-control group comparison revealed small } \\
\text { effects and spatially limited differences. }\end{array}$ \\
\hline (69) & $\begin{array}{c}\text { Lab } \\
\text { specific }\end{array}$ & $\begin{array}{l}44 \mathrm{ASD} \\
44 \mathrm{NT}\end{array}$ & $\begin{array}{l}10 \pm 4 / \text { gr } \\
\text { oup }\end{array}$ & 33 (75)/group & $\mathrm{NM}^{\mathrm{i}}$ & $\begin{array}{l}\quad E E G ; \\
\text { age-related } \\
\text { alpha wave }\end{array}$ & sMRI volume & 2 & $\begin{array}{c}\uparrow \text { magnitude of alpha waves deviation in ASD vs NT. } \\
\text { Correlation between regional volume and alpha } \\
\text { frequency did not survive statistical correction. Case } \\
\text { control did not yield any group differences. }\end{array}$ \\
\hline
\end{tabular}

TABLE 1. ASD neurosubtyping studies in humans. $\boldsymbol{a}$ : only the sample being neurosubtyped is reported; $\boldsymbol{b}$ : mean age and standard deviation is used when age-range was not reported. c: reporting validation based on domains distinct from the features originally used to identify neurosubtypes (NSs); d: 303 NT from ADHD-200, 349 form ABIDE I; $\boldsymbol{e}$ : NT sample (N=348) from ABIDEII+GENDAAR was used to generate iFC $z$-scores in ASD; $\mathbf{f : ~} n=870$ NT data were used to build the normative model; g: Latent factor analysis (LFA) used a Bayesian model based on Latent Dirichlet Allocation; $\boldsymbol{h}$ : normative modeling (NM) was based on Gaussian process regression; $\boldsymbol{i}$ : NM was based on local polynomial regression; $\boldsymbol{j}$ : Regions of interest (ROI) were based on the Dosenbach atlas (151); $\boldsymbol{k}$ : ROI included (genu, splenium and corpus of the corpus callosum, hippocampus, head of the caudate and amygdala; $\boldsymbol{l}$ : ROI included nodes of the 
default network (DN), salience network (SN), and dorsal attention network (DAN) selected based on metanalyses; m: ROI included the 400 cortical parcellations per Schaefer, et al. (152) and 18 subcortical Freesurfer parcellations. Abbreviations: ADOS: Autism Diagnostic Observation Schedule; ASD: Autism spectrum disorder; BD: Bipolar disorder; CARS: childhood autism rating scale; CBCL: child behavior checklist; CC: corpus callosum; CT: cortical thickness; FA: fractional anisotropy; FDR: false discovery rate; FA: fractional anisotropy; GD: geodesic distance; GMV: gray matter volume; IC: intensity contrast; iFC: intrinsic functional connectivity; MD: mean diffusivity; NA: not applicable; NMF: non-negative matrix factorization; NR: not reported; PLS: partial least squares: RRB: restricted repetitive behavior; SA: surface area; SCV: subcortical volume; SNF: similarity network fusion; SSD: Schizophrenia spectrum disorders; visual network (VN).

\begin{tabular}{|c|c|c|c|c|c|c|c|c|c|}
\hline Source & Descriptor & Design & Sample N & Age (y) & $\begin{array}{l}\text { Imaging } \\
\text { Modality }\end{array}$ & $\begin{array}{l}\text { Phenotypic and } \\
\text { other data }\end{array}$ & Open & Ongoing & Neurosubtyping Use \\
\hline ABIDE $\mathbf{I}^{\mathbf{a}}$ & $\begin{array}{l}\text { Previously collected } \\
\text { neuroimaging \& } \\
\text { phenotypic data across } \\
17 \text { sites using } \\
\text { independent protocols. } \\
\text { Data released in August } \\
\text { 2012. (75) }\end{array}$ & CS & $\begin{array}{c}539 \text { ASD, } 573 \\
\text { NT }\end{array}$ & $7-64$ & $\begin{array}{l}\text { sMRI, R- } \\
\text { fMRI }\end{array}$ & $\begin{array}{l}\text { Demographics, } \\
\text { ADOS, IQ, } \\
\text { partially enhanced } \\
\text { (e.g., ADI-R } \\
\text { comorbidity } \\
\text { measures) in some } \\
\text { sites* }\end{array}$ & Yes & No & \multirow{2}{*}{$\begin{array}{l}\text { - Multimodal neurosubtyping } \\
\text { within ASD diagnosis or across } \\
\text { both ASD and NT. } \\
\text { - Existing but limited non- } \\
\text { neuroimaging data available for } \\
\text { validation or data fusion. } \\
\text { - Open sharing facilitates } \\
\text { independent replications of } \\
\text { findings in more deeply } \\
\text { phenotype datasets. }\end{array}$} \\
\hline ABIDE II $^{\mathrm{b}}$ & $\begin{array}{l}\text { Previously collected } \\
\text { imaging and phenotypic } \\
\text { data across } 19 \text { sites } \\
\text { using independent } \\
\text { protocols. Data released } \\
\text { in June 2016. (75) }\end{array}$ & $\begin{array}{l}\text { Largely CS } \\
\text { (Long. in } 2 \\
\text { sites) }\end{array}$ & $\begin{array}{c}521 \mathrm{ASD}, 593 \\
\mathrm{NT}\end{array}$ & $5-64$ & $\begin{array}{l}\text { sMRI, R- } \\
\text { fMRI, (DTI } \\
\text { for selected } \\
\text { sites) }\end{array}$ & $\begin{array}{l}\text { Partially enhanced } \\
\text { phenotypic } \\
\text { information } \\
\text { relative to ABIDE I }\end{array}$ & Yes & No & \\
\hline NDAR $^{c}$ & $\begin{array}{l}\text { Retrospective and } \\
\text { ongoing collections } \\
\text { from multiple } \\
\text { independent } \\
\text { studies/protocols. (79) }\end{array}$ & $\begin{array}{l}\text { Vary by } \\
\text { project, } \\
\text { include CS } \\
\text { and Long. }\end{array}$ & $\begin{array}{l}\text { Vary by project, } \\
\text { ASD, NT and } \\
\text { other diagnoses }\end{array}$ & $\begin{array}{l}\text { varying } \\
\text { by study }\end{array}$ & $\begin{array}{l}\text { Multi-modal } \\
\text { imaging, } \\
\text { varying by } \\
\text { study }\end{array}$ & $\begin{array}{l}\text { Psychiatric, other } \\
\text { phenotypes; } \\
\text { genetics and other } \\
\text { metrics vary by } \\
\text { study }\end{array}$ & Yes & Mixed & $\begin{array}{l}\text { - Multimodal neurosubtyping } \\
\text { within ASD diagnosis or across } \\
\text { both ASD and NT and/or } \\
\text { multiple diagnoses. } \\
\text { - Multidimensional phenotypic } \\
\text { data available for validation } \\
\text { along with other objective } \\
\text { markers but availability is } \\
\text { highly variable across studies. } \\
\text { - Open sharing facilitates } \\
\text { independent replications of } \\
\text { findings, may need }\end{array}$ \\
\hline
\end{tabular}




\begin{tabular}{|c|c|c|c|c|c|c|c|c|c|}
\hline & & & & & & & & & $\begin{array}{l}\text { independent, more deeply } \\
\text { phenotype datasets }\end{array}$ \\
\hline $\begin{array}{l}\text { EU-AIMS- } \\
\text { LEAPd }^{d}\end{array}$ & $\begin{array}{c}\text { Large-scale prospective } \\
\text { multicenter (7 site) data } \\
\text { collection (2014-2016) } \\
\text { (77) }\end{array}$ & $\begin{array}{l}\text { Long. ( } 61 \% \\
\text { of baseline } \\
\text { data } \\
\text { completed } \\
\text { follow-up } \\
\text { assessments) }\end{array}$ & $\begin{array}{l}437 \text { ASD, } \sim 300 \\
\text { NT and mild ID, } \\
36 \text { ASD twins, } \\
36 \text { NT twins }\end{array}$ & $6-30$ & $\begin{array}{l}\text { sMRI, } \\
\text { FLAIR, DTI } \\
\text { R-fMRI, T- } \\
\text { fMRI, EEG }\end{array}$ & $\begin{array}{l}\text { Clinical symptom, } \\
\text { comorbidities, } \\
\text { quality of life, } \\
\text { neurocognitive, } \\
\text { biochemical, } \\
\text { prenatal } \\
\text { environmental risk } \\
\text { factors and } \\
\text { genomics }\end{array}$ & No & Yes & $\begin{array}{l}\text { Multimodal neurosubtyping } \\
\text { within ASD diagnosis or across } \\
\text { both ASD and NT and/or ID. } \\
\text { - ASD-specific multidimensional } \\
\text { phenotypic data available for } \\
\text { validation or data fusion along } \\
\text { with other objective markers } \\
\text { (e.g., eye tracking). } \\
\text { - Longitudinal data in }>61 \% \text { of } \\
\text { cases, allow to use behavioral } \\
\text { outcomes for validation and } \\
\text { brain trajectories for subtyping }\end{array}$ \\
\hline $\mathbf{H B N}^{\mathrm{e}}$ & $\begin{array}{l}\text { Community self- } \\
\text { referred multi-omic } \\
\text { dataset, aiming to } \\
\text { 10,000 individuals from } \\
\text { the New York (NY, } \\
\text { USA) metropolitan } \\
\text { area. (153) }\end{array}$ & $\mathrm{CS}$ & $\begin{array}{l}\text { Transdiagnostic } \\
(16 \% \text { ASD }), \text { NT; } \\
\text { To date } \sim 3000 \\
\text { data collected, } \\
\sim 2000 \text { openly } \\
\text { released }\end{array}$ & $5-21$ & $\begin{array}{l}\text { sMRI, R- } \\
\text { fMRI, } \\
\text { naturalistic } \\
\text { viewing- } \\
\text { fMRI, T- } \\
\text { fMRI, EEG }\end{array}$ & $\begin{array}{c}\text { psychiatric, } \\
\text { behavioral, } \\
\text { cognitive, and } \\
\text { lifestyle } \\
\text { phenotypes; eye- } \\
\text { tracking, voice and } \\
\text { video recordings, } \\
\text { genetics and } \\
\text { actigraphy }\end{array}$ & Yes & Yes & $\begin{array}{l}\text { Multimodal neurosubtyping } \\
\text { within ASD diagnosis or across } \\
\text { both ASD and NT and/or } \\
\text { multiple diagnoses. } \\
\text { - Extended multidimensional } \\
\text { phenotypic datasets available } \\
\text { for validation or data fusion } \\
\text { along with other objective } \\
\text { markers (e.g., eye tracking). } \\
\text { - Open sharing facilitates } \\
\text { independent data replications } \\
\text { also using split samples. }\end{array}$ \\
\hline POND $^{f}$ & $\begin{array}{c}\text { A clinical } \\
\text { multidiscipline study of } \\
\text { the neurobiology of } \\
\text { multiple } \\
\text { neurodevelopment } \\
\text { disorders. } \\
\text { (154) }\end{array}$ & $\begin{array}{l}\text { CS; Long. } \\
\text { treatment in } \\
\text { subsamples }\end{array}$ & $\begin{array}{l}\text { Transdiagnostic } \\
\text { (ASD, OCD, } \\
\text { ADHD, ID, } \\
\text { unknown genetic } \\
\text { syndromes) }\end{array}$ & $\begin{array}{l}\text { school- } \\
\text { age }\end{array}$ & $\begin{array}{l}\text { sMRI, R- } \\
\text { fMRI, T- } \\
\text { fMRI, MEG }\end{array}$ & $\begin{array}{l}\text { psychiatric, } \\
\text { behavioral, } \\
\text { cognitive }\end{array}$ & No & Yes & $\begin{array}{l}\text { - Multimodal neurosubtyping } \\
\text { within ASD diagnosis or across } \\
\text { diagnoses. } \\
\text { - Multidimensional phenotypic } \\
\text { dataset available for validation }\end{array}$ \\
\hline
\end{tabular}




\begin{tabular}{|c|c|c|c|c|c|c|c|c|c|}
\hline NKI-RS & $\begin{array}{l}\text { Community-ascertained } \\
\text { life span sample. }(80)\end{array}$ & CS; Long. & 1000 Largely NT & $6-65$ & $\begin{array}{l}\text { sMRI, R- } \\
\text { fMRI }\end{array}$ & $\begin{array}{l}\text { physiological, } \\
\text { psychological, } \\
\text { genetic data }\end{array}$ & Yes & Mixed & $\begin{array}{l}\text { Multimodal neurosubtyping of } \\
\text { NT variance across multiple } \\
\text { psychological domains } \\
\text { including ASD-associated } \\
\text { traits. } \\
\text { The restricted number of } \\
\text { individuals with ASD limits the } \\
\text { assessment of ASD specificity. } \\
\text { Longitudinal outcome available } \\
\text { for validation }\end{array}$ \\
\hline $\begin{array}{l}\text { Generation } \\
\text { R/R Next }\end{array}$ & $\begin{array}{l}\text { Population-based } \\
\text { prospective multi- } \\
\text { ethnic cohort from in } \\
\text { the Rotterdam (NL) } \\
\text { metropolitan area. } \\
\text { eligibility: pregnant } \\
\text { women with an } \\
\text { expected delivery date } \\
\text { between } 2002 \text { and } \\
\text { 2006; long-term follow- } \\
\text { up design (78) }\end{array}$ & Long. & $\begin{array}{l}\text { Largely NT, a } \\
\text { small proportion } \\
\text { of children have } \\
\text { ASD confirmed } \\
\text { at age 6-9 years } \\
\text { based on review } \\
\text { of medical } \\
\text { records. }\end{array}$ & fetal-16 & $\begin{array}{l}\text { Ultrasound } \\
\text { (pre-birth); } \\
\text { sMRI, DTI, } \\
\text { R-fMRI } \\
\text { collected } \\
\text { after age } 6 \\
\text { years }\end{array}$ & $\begin{array}{l}\text { Health outcome, } \\
\text { environmental, } \\
\text { endocrine, } \\
\text { genomic, lifestyle, } \\
\text { nutritional, socio- } \\
\text { demographic } \\
\text { determinants }\end{array}$ & No & Yes & $\begin{array}{l}\text { - Multimodal neurosubtyping of } \\
\text { NT variance across multiple } \\
\text { psychological domains } \\
\text { including ASD-associated traits. } \\
\text { - The restricted number of } \\
\text { individuals with ASD may limit } \\
\text { the assessment of ASD } \\
\text { specificity. } \\
\text { - Extensive longitudinal data } \\
\text { offers outcome for } \\
\text { neurosubtyping validation. }\end{array}$ \\
\hline
\end{tabular}

TABLE 2. Selected Imaging Datasets Usable for Neurosubtyping. $\boldsymbol{a}$ : http://fcon_1000.projects.nitrc.org/indi/abide/abide_I.html; $\boldsymbol{b}$ :

http://fcon_1000.projects.nitrc.org/indi/abide/abide_II.html; $\boldsymbol{c}$ : https://nda.nih.gov/about.html; $\boldsymbol{d}$ : https://www.eu-aims.eu; e:

http://fcon_1000.projects.nitrc.org/indi/cmi_healthy_brain_network/; $\boldsymbol{f}$ : https://pond-network.ca; $\boldsymbol{g}$ : http://fcon_1000.projects.nitrc.org/indi/enhanced/; $\boldsymbol{h}$ : https://generationr.nl/. ABIDE: Autism Brain Imaging Data Exchange; ADOS: Autism Diagnostic Observation Schedule; ADI-R: Autism Diagnostic Interview-Revised; ASD: Autism spectrum disorder; CS: cross sectional design; DTI; diffusion tensor Imaging; Dx; Diagnoses; EU-AIMS-LEAP: European Autism Interventions Longitudinal European Autism Project; FLAIR: Fluid attenuated inversion recovery image; HBN: Healthy Brain Network; ID; Intellectual disability; IQ: Intellectual quotient; Long; Longitudinal; MEG:

Magnetoencephalography; MRI: magnetic resonance imaging; NDAR: National Database for Autism Research; NKI-RS: Enhanced Nathan Kline Institute-Rockland Sample; NL: Netherlands; NY: New York; NT: neurotypical; POND: Province of Ontario Neurodevelopmental Disorders; R-fMRI; resting-state functional MRI; sMRI: structural MRI; TfMRI: Task-based functional MRI. 


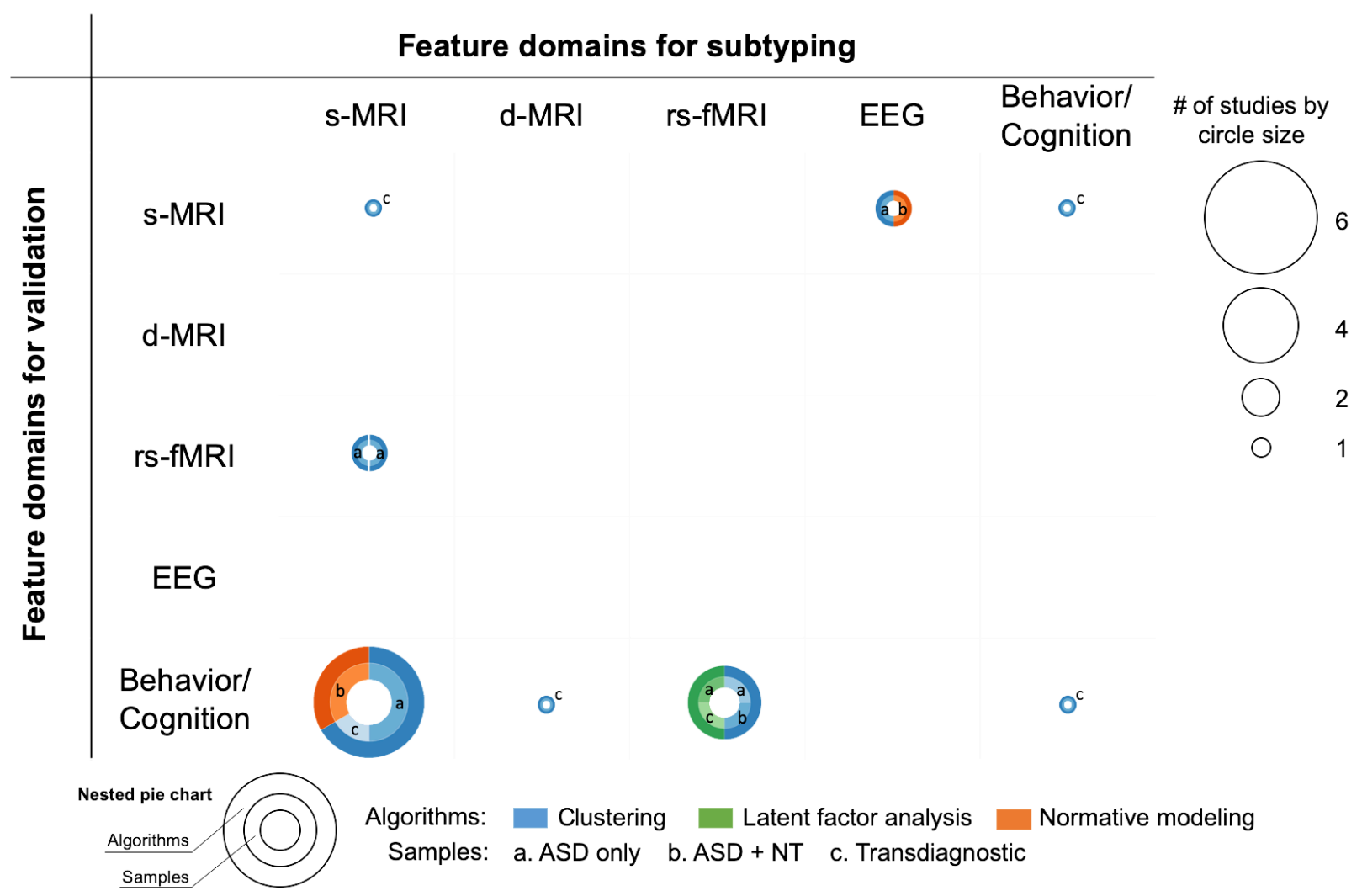

Figure 1. Minimally overlapping neurosubtyping research designs in Autism Spectrum Disorder (ASD). 
A. Diagnostic samples

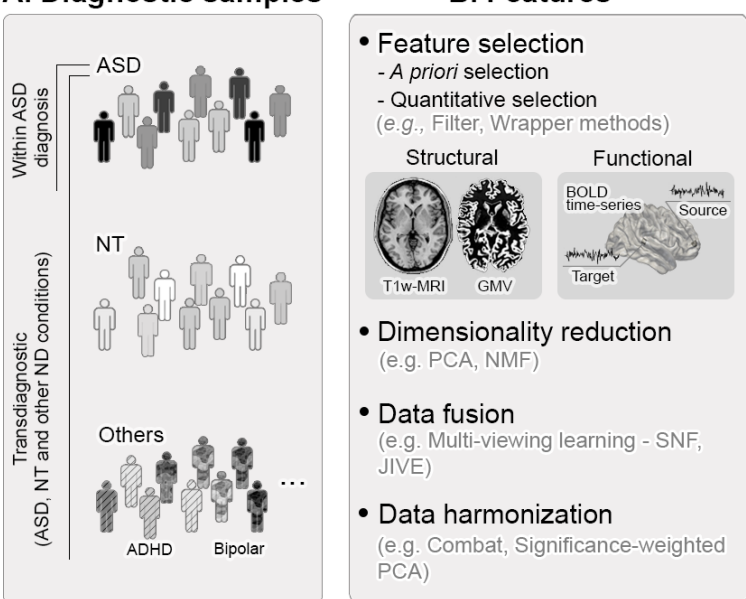

C. Algorithms

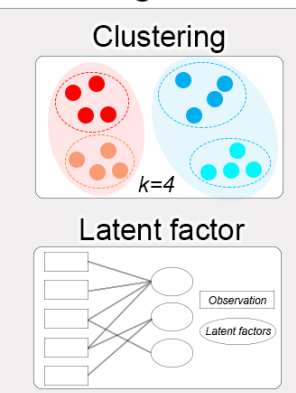

Normative modeling

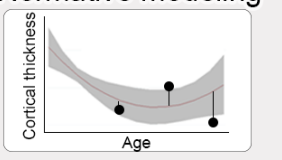

\section{Validation}

- Goodness of fit

- Silhouette, Davies-Bouldin index

- Stability

- Cross-method validation, Bootstrapping

- Independent validation - Clinical (e.g., symptom severity ADOS, ADI-R)

- Cognitive (neuropsychological scores)

- Biological (genetics profile - CNV,

common/rare variants)

- Replicability

- Bootstrap aggregation (Bagging)

- Cross-modal validation (e.g., functional

connectivity or structural metrics)

- Independent samples

FIGURE 2. Key methodological steps in neurosubtyping. 